\title{
Visual Evoked Potentials in Guillain-Barré Syndrome
}

\author{
Levent Güngör, ${ }^{a}$ İnci Güngör, ${ }^{b}$ Hilal Eser Öztürk, ${ }^{b}$ Musa Kazım Onar ${ }^{a}$ \\ ${ }^{a}$ Departments of Neurology and ${ }^{\mathrm{b}}$ Ophthalmology, Ondokuz Mayis University School of Medicine, Samsun, Turkey
}

Received June 17, 2010

Revised August 17, 2010

Accepted August 17, 2010

\section{Correspondence}

Levent Güngör

Department of Neurology,

Ondokuz Mayıs University

School of Medicine,

55139 Samsun, Turkey

Tel +9-0-362-3121919-3715

Fax +9-0-362-4576757

E-mail ligungor@omu.edu.tr
Background and Purpose Guillain-Barré syndrome (GBS) is an acute demyelinating polyneuropathy with various clinical features. Optic neuritis occurs in rare cases. In this study we determined the incidence and patterns of visual evoked potential (VEP) abnormality in GBS in association with ophthalmologic findings.

Methods Thirty-two patients with a diagnosis of GBS were included in the study. The correlation between pathologic VEPs and categories of neurologic deficit and electrophysiological findings were examined statistically.

Results The patients ranged in age from 19 to 77 years. Five cases (16\%) had abnormal VEPs. All five of these patients exhibited increased P100 latency differences between the two eyes. Other abnormalities were prolonged p100 latency, increased interocular amplitude difference, and distorted p100 configuration. Pathologic signs on ophthalmologic examination were observed in $80 \%$ of patients with abnormal VEPs. VEP abnormality was never present in pure axonal forms. There was no significant correlation between pathologic VEP and cerebrospinal fluid protein level or categories of neurologic deficits.

Conclusions Involvement of the optic pathways is not a frequent finding in GBS. When present it is always asymmetric and generally accompanied with pathologic findings on ophthalmologic examination. VEPs may be abnormal in different clinical variants of GBS, and especially in demyelinating forms.

J Clin Neurol 2011;7:34-39

\section{Introduction}

Guillain-Barré syndrome (GBS) is the most common cause of acute polyneuropathy. The clinical-pathologic spectrum of GBS extends from the classical acute inflammatory demyelinating polyneuropathy (AIDP) to pure axonal variants with (acute motor sensory axonal neuropathy) and without (acute motor axonal neuropathy) sensory involvement, and clinical variants such as the Miller Fisher syndrome (MFS). Cranial-nerve involvement, dysautonomia, and respiratory insufficiency may be seen during the course of the disease. ${ }^{1,2}$ Although the cranial nerves are often involved in GBS, the optic nerves are usually spared, presumably because they are part of the central nervous system (CNS). ${ }^{3}$

A few studies have revealed optic-nerve involvement and evoked potential abnormalities in GBS. ${ }^{4-7}$ In the present study we determined the incidence of visual pathway involvement in GBS with the aid of clinical and electrophysiological assess- ment, and defined the patterns of visual evoked potential (VEP) abnormalities in GBS.

\section{Methods}

Thirty-two patients with a diagnosis of GBS at the Department of Neurology, Ondokuz Mayıs University Health and Research Hospital between April 2005 and December 2009 were included in the study. All patients met the diagnostic criteria for GBS, as defined previously, based on clinical evaluation, nerve conduction studies, and cerebrospinal fluid (CSF) investigation. ${ }^{8-10}$ All patients had symptomatic motor or sensory neuropathy with acute onset. Electrophysiological data were consistent with demyelinating, axonal, or mixed polyneuropathy; no other etiology of acute neuropathy was detectable. All patients gave their informed consent to participate in the study. Patients with severe motor, bulbar, or autonomic involvement causing cardiopulmonary instability and needing intensive life support and monitor- 
ing, or who died early during the course of illness were excluded.

The neurologic findings of each patient were outlined in six categories with the aid of neurologic examination:

1) Superficial (any deficiency of light-touch, pinprick, or temperature sensation) and deep (vibratory sensation or position sense) sensorial loss.

2) Motor deficit (decrease in upper or lower extremity muscle strength).

3) Presence of limb ataxia.

4) Cranial-nerve involvement (other than the optic nerve).

5) Autonomic involvement.

Routine blood tests and CSF examination were performed. The clinical syndrome was defined according to electrophysiological and clinical findings.

A pattern reversal-VEP study was carried out for all patients as early as possible when clinical cooperation with the test was technically available. The stimulation source was a black/white full-field checkerboard pattern on a television screen with check size of 14 inches, a reversal rate of $1 \mathrm{~Hz}$, and a Michelson contrast of $99 \%$. The television screen was positioned $1 \mathrm{~m}$ from the eyes. Each eye was tested separately and with the opposite eye occluded. The VEPs were recorded by epicranial surface electrodes. The active electrode was placed over the midocciput $(\mathrm{Oz})$ and referred to as the midfrontal lead $(\mathrm{Fz})$. The ground electrode was placed at the vertex $(\mathrm{Cz})$. A bandpass filter $(0.1-$ $1 \mathrm{~Hz}$ ) was used with a sweep speed of $300 \mathrm{msec} .{ }^{11,12}$ In total, 375 responses were recorded for each eye and averaged by a computer system (Dantec Keypoint, Medtronic Functional Diagnostics, Skovlunde, Denmark). Two trials were performed under the same stimulation conditions for each subject to confirm the reproducibility. The latencies and amplitudes of the N75, P100, and N145 waves, the P100 morphology, and differences in the latency and amplitude of the P100 wave between the two eyes were evaluated. The latencies and amplitudes were evaluated according to normal values from our laboratory obtained from 160 healthy subjects (114 females and 46 males) aged between 19 and 72 years. The following were considered to be abnormal: P100 latencies $>2.5$ standard deviations above the mean of the normal population $(>108$ msec for patients younger than 50 years, and $>116 \mathrm{msec}$ for males and $>109 \mathrm{msec}$ for females older than 50 years), minimal left-to-right amplitude ratio $>0.66$, and left-right difference of latency $>6$ msec for the P100 peak.

Each patient underwent a detailed ophthalmologic examination performed by an ophthalmologist who was blinded to the VEP results. Anterior segment evaluation, visual acuity, presence of pupillary light-reflex abnormalities (total loss, anisocoria, or relative afferent pupillary defect), fundoscopic findings, and defects of colored vision were recorded. Patients who had diseases that may affect VEP results, such as severe refractive error, glaucoma, optic media opacity, retinal disease, or previous history of optic neuropathy, were excluded.

Any correlations between the presence of pathologic VEPs and any category of neurologic deficit, electrophysiological data, or CSF protein level were examined. Fisher's exact, Student's t, and Mann-Whitney U tests were used for statistical analyses.

\section{Results}

The patients ranged in age from 19 to 77 years (mean \pm SD: $50.13 \pm 16.02$ years). There were 19 males (59\%) and $13 \mathrm{fe}-$ males $(41 \%)$. The diagnosis was AIDP in 18 patients $(56 \%)$, MFS in $5(16 \%)$, acute motor sensory axonal neuropathy in 5 $(16 \%)$, and acute motor axonal neuropathy in $4(13 \%)$, based on clinical and electrophysiological findings. Twenty-one patients $(66 \%)$ were treated with intravenous immunoglobulin and $4(13 \%)$ were treated with plasmapheresis.

The time interval between the onset of symptoms and the VEP study ranged from 6 to 45 days. VEPs were abnormal in five cases (15.63\%) (Fig. 1). The most common abnormality was increased interocular latency difference (7-20 msec), which was present in all five cases. P100 latency was delayed in four cases (12.50\%), of which two had prolonged P100 latency in both eyes $(6.25 \%)$. Other abnormalities were distorted (W-shaped) P100 configuration and increased interocular amplitude difference (two cases, 6.25\%) (Table 1). N75 and N145 were significantly prolonged in only one patient $(3.13 \%)$. Visual examination was abnormal in four of the five patients with abnormal VEPs (80\%). Of those with abnormal VEPs, there was decrease in visual acuity in four patients $(80 \%)$, light-reflex abnormalities or afferent pupillary defect in three $(60 \%)$, dyschromatopsia in one (20\%), and papilledema in one (20\%) (Table 1). Among those with normal VEPs, only one patient had light-reflex abnormality (3.13\%), and two had unexplained decreases in visual acuity $(6.25 \%)$. One patient with prolonged P100 in one eye had unexplained decreased visual acuity and dyschromatopsia in the contralateral eye.

Three of the patients with abnormal VEPs were female (60\%), four had a diagnosis of AIDP (80\%), and one was diagnosed with MFS (20\%) (Table 1). Pathologic VEPs were obtained only in patients with electrophysiological findings suggesting demyelinating peripheral neuropathy, but not axonal forms. None of the clinical deficits observed on neurologic examination was significantly correlated with VEP pathology (Table 2). Superficial sensorial deficit ( $60 \%$ versus $88.89 \%$ ) and cranialnerve involvement other than the optic nerve (40\% versus 44 . $44 \%$ ) appeared to be less prevalent, and autonomic involvement ( $20 \%$ versus $18.52 \%$ ) slightly more common in GBS patients with abnormal VEPs, but the difference did not reach statistical 


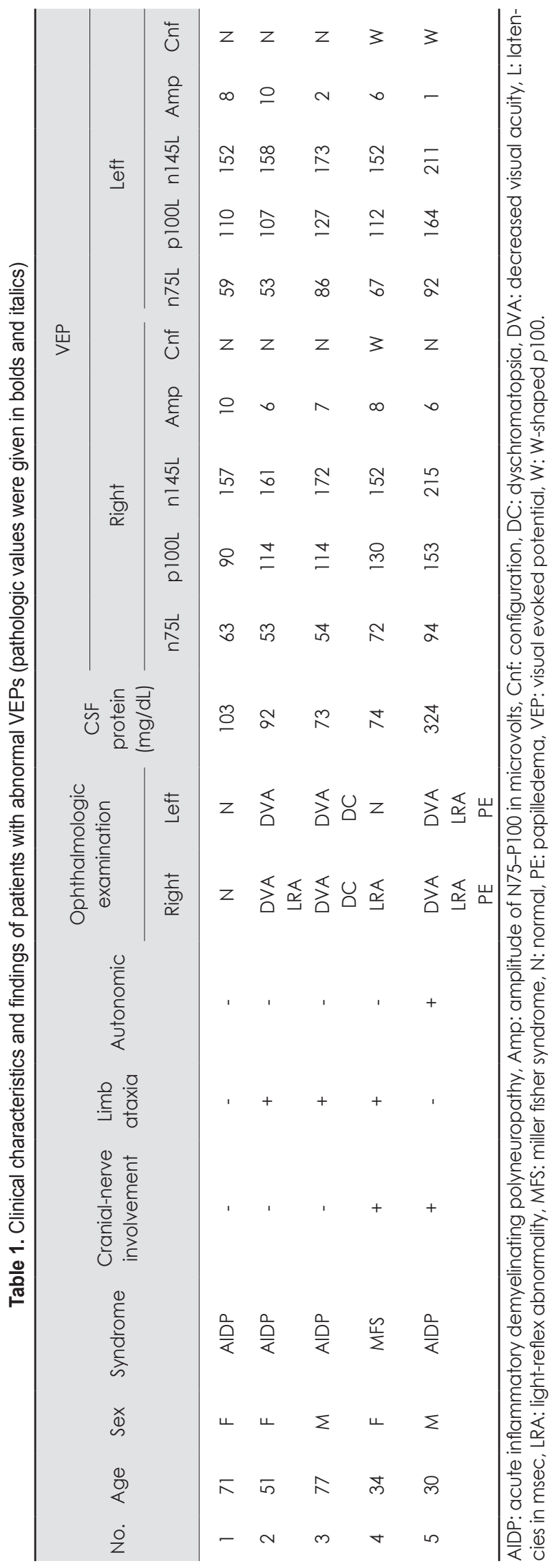

significance $(p>0.05)$. All of the patients with pathologic VEPs had deep sensorial loss and motor involvement, while among those with normal VEPs, $51.85 \%$ had deep sensorial loss and $85.19 \%$ had motor loss $(p>0.05)$. Limb ataxia, which could be evaluated in 24 patients, was more common in those with abnormal VEPs, but the difference was not statistically significant ( $75 \%$ versus $30 \%, p>0.05$ ). CSF protein levels tended to be higher in GBS patients with pathologic VEPs, but again the difference did not reach statistical significance (133.2 versus 85.70 $\mathrm{mg} / \mathrm{dL}$ ) (Table 2).

\section{Discussion}

GBS is an acute, rapidly progressive, symmetrical polyradiculoneuropathy that is characterized by weakness, areflexia, sen-

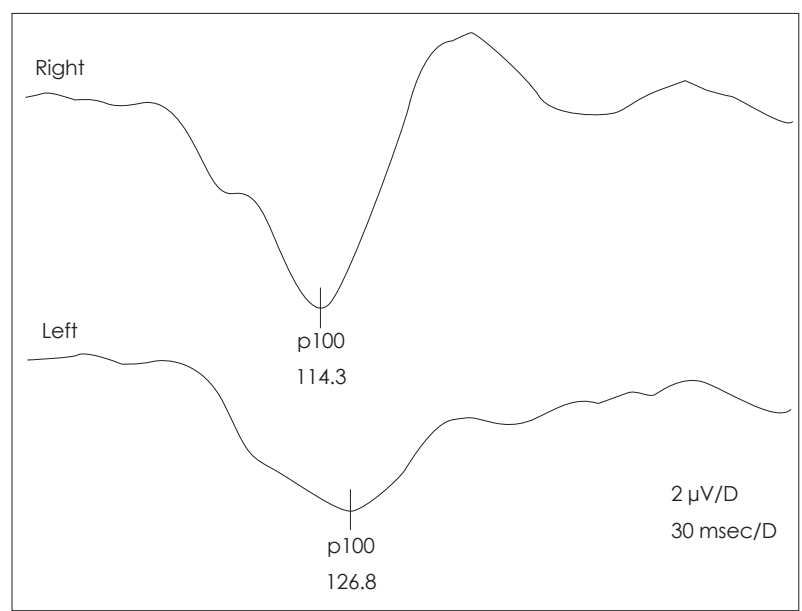

Fig. 1. Pathologic VEP of a patient with GBS (no. 3). The P100 latency is elongated on the left side, and has a low amplitude (lower trace), while it is normal on the right side (upper trace).

Table 2. Comparison of clinical characteristics and CSF protein levels in GBS patients with abnormal and normal VEPs

\begin{tabular}{|c|c|c|c|c|c|}
\hline & Abnor & al VEP & Norm & al VEP & $n$ \\
\hline & No. & $\%$ & No. & $\%$ & $r$ \\
\hline Female sex & $3 / 5$ & 60 & $10 / 27$ & 37.04 & $>0.05$ \\
\hline $\begin{array}{l}\text { Cranial-nerve } \\
\text { involvement }\end{array}$ & $2 / 5$ & 40 & $12 / 27$ & 44.44 & $>0.05$ \\
\hline Motor deficit & $5 / 5$ & 100 & $17 / 27$ & 85.19 & $>0.05$ \\
\hline $\begin{array}{l}\text { Superficial sensorial } \\
\text { loss }\end{array}$ & $3 / 5$ & 60 & $24 / 27$ & 88.89 & $>0.05$ \\
\hline Deep sensorial loss & $5 / 5$ & 100 & $14 / 27$ & 51.85 & $>0.05$ \\
\hline Ataxia & $3 / 4$ & 75 & $6 / 20$ & 30 & $>0.05$ \\
\hline $\begin{array}{l}\text { Autonomic } \\
\text { involvement }\end{array}$ & $1 / 5$ & 20 & $5 / 27$ & 18.52 & $>0.05$ \\
\hline $\begin{array}{l}\text { Demyelinating } \\
\text { neuropathy }\end{array}$ & $5 / 5$ & 100 & $18 / 27$ & 66.67 & $>0.05$ \\
\hline CSF protein $(\mathrm{mg} / \mathrm{dL})$ & 5 & $133.2^{*}$ & 26 & $85.7^{*}$ & $>0.05$ \\
\hline
\end{tabular}


sorial loss, and albuminocytologic dissociation in the CSF. Ataxia and dysautonomia may also be seen. ${ }^{1,6}$ Cranial-nerve involvement may form part of the disease, especially in MFS. Ophthalmoparesis, facial weakness, or bulbar paralyses are common in patients with GBS, but optic-nerve involvement is less common.

Morley and Reynolds first drew attention to the probability of optic neuritis in GBS in $1966 .{ }^{13}$ Behan subsequently reported a case of GBS with bilateral decreased visual acuity to 20/70, dyschromatopsia, and optic disc swelling. ${ }^{14}$ Later clinical series and case reports have identified patients with GBS accompanied by optic neuritis. In the study of Mori, which included 45 patients, $42 \%$ had mydriasis and light-reflex abnormalities, and approximately $50 \%$ had anisocoria. ${ }^{15}$ Decreased visual acuity, ${ }^{7,16,17}$ total blindness, ${ }^{18}$ RAPD or other pupillary dysfunctions, ${ }^{17,19-22}$ dyschromatopsia, ${ }^{7,14,20,23}$ enlarged blind spot, ${ }^{7}$ centrocecal scotoma, ${ }^{16}$ temporal peripheral field constriction, ${ }^{21,24}$ and optic disc swelling ${ }^{16,17,25-27}$ have been described in patients with GBS. Some cases with optic neuritis may also have cerebral parenchymal abnormalities on MRI. ${ }^{28,29}$

Pathologies of the optic pathway are best demonstrated by VEP evaluation. The incidence of VEP abnormalities has been investigated in chronic inflammatory demyelinating neuropathy, and reportedly varies between $44 \%$ and $86 \% .{ }^{30-32}$ Four previous studies examined the incidence of VEP abnormalities in GBS patients. Topçu et al. ${ }^{7}$ described VEP abnormalities in $33.33 \%$ of GBS patients in the pediatric age group. Zgorzalewicz et al. ${ }^{5}$ found elongation of P100 or N145 in $5(17 \%)$ of 30 patients diagnosed with GBS between the ages of 8 and 18 years. In addition to these cases, Wong et al. ${ }^{6}$ found no VEP abnormality in his four pediatric cases, and only one with light-reflex abnormality. Finally, Durand et al. found a VEP abnormality in only one of nine adults with MFS (11\%). ${ }^{4}$

In the present study we found abnormal VEPs in $16 \%$ of patients diagnosed with GBS. This rate is similar to that found for a pediatric group and adults with MFS. To our knowledge, the present study is the largest trial demonstrating VEP pathologies in adult GBS patients. Previously reported VEP abnormalities in GBS patients are absent VEPs ${ }^{28} \mathrm{P} 100$ elongation, $7,20,24,27,33,34$ N145 latency elongation, ${ }^{5}$ and alterations in P100 morphology. ${ }^{25} \mathrm{P} 100$ latencies differed significantly between the two sides in all of our patients with pathologic VEPs, suggesting that if it is present, optic-nerve or postchiasmal involvement is always asymmetric. The other VEP abnormalities noted among our patients were elongation of the P100 latency in most of those with normal N75 latencies, distorted P100 configuration (W shaped), and pathologic differences in amplitudes between the two sides.

Nearly all of the patients in our study with abnormal VEPs had abnormal findings in ophthalmologic examinations: decre- ased visual acuity, RAPD, loss of light reflex, dyschromatopsia, and papilledema. One of our patients had light-reflex abnormality but normal VEPs. Fuller et al. ${ }^{35}$ also described a patient with severe demyelinating GBS and unreactive pupils, but with normal VEPs and a microscope examination revealing no demyelination in the optic nerve. It is thus impossible to conclude that all patients with pupillary dysfunction have prechiasmatic optic-nerve involvement. The N75, P100, and N145 waves recorded during our VEP study are known to originate from the striate cortex. ${ }^{36}$ Light-reflex abnormalities accompanied abnormal P100 latencies in $60 \%$ of our patients, suggesting involvement of the optic nerve. For a diagnosis of optic neuritis, light-reflex abnormalities must be accompanied with other ophthalmologic findings, such as decreases in visual acuity or dyschromatopsia and VEP abnormality. Our results also show that VEPs may be abnormal in GBS cases without visual complaints or ophthalmologic findings, suggesting the presence of central lesions in the visual pathways; however, the presence of brain lesions was not investigated in the present study.

Involvement of the second cranial nerve in GBS may be related to infectious agents such as Mycoplasma pneumoniae, $17,18,25,34$ cytomegalovirus, ${ }^{3}$ Epstein-Barr virus, ${ }^{28}$ mumps virus, ${ }^{37}$ and herpes simplex virus type $\mathrm{I}^{20}$ Isolated optic neuritis may develop after mycoplasma infection. ${ }^{38}$ This correlation with infectious agents was not investigated in our study.

The cases reported in the literature give the impression that optic-nerve involvement accompanies MFS. . $19,23,24,26,29,39$ The human optic nerve contains high levels of sulfated glucuronyl glycolipids and gangliosides such as GD1b, GQ1b, and GT1b. ${ }^{40,41}$ The involvement of both peripheral and optic nerves in GBS may result from these shared pathogenic epitopes. ${ }^{21,42}$ The amount of CNS involvement is greater in MFS than in GBS. Optic-nerve involvement may be part of a spectrum of CNS involvement. ${ }^{43}$ We were unable to find a significant association with optic pathway involvement and the MFS variant of GBS, although deep sensorial loss and limb ataxia were more prevalent among our patients with abnormal VEPs.

None of our patients with axonal GBS had abnormal VEPs, which may be attributable to the low sensitivity of the VEP study to axonal damage in the optic nerve. Although not statistically significant, the involvement of the motor and autonomic nervous systems was more prevalent in our GBS patients with abnormal VEPs, while superficial sensorial loss and involvement of other cranial nerves were less common. In addition, there was no significant correlation between CSF protein levels and VEP abnormalities. These differences between groups might not have reached statistical significance due to the very small number of patients with pathologic VEPs evaluated in the present study. It should also be emphasized that patients with severe deficits or who are early along the course of the ill- 
ness were not included in this study.

VEPs may be abnormal in GBS, but this is not a frequent occurrence. The findings of our study underline the possibility of visual pathway involvement in GBS. If present, visual pathway involvement is always asymmetric. VEPs may be abnormal in only the demyelinating forms of GBS. VEP studies together with detailed ophthalmologic examinations supply important information regarding optic-nerve involvement in GBS. However, the clinical correlation between optic-nerve involvement and the prognosis is unclear, and remains an area for future investigation.

\section{Conflicts of Interest}

The authors have no financial conflicts of interest.

\section{REFERENCES}

1. Hughes RA, Hadden RD, Gregson NA, Smith KJ. Pathogenesis of Guillain-Barré syndrome. J Neuroimmunol 1999;100;74-97.

2. Hartung HP, Kieseier BC, Kiefer R. Progress in Guillain-Barré syndrome. Curr Opin Neurol 2001;14:597-604.

3. Igarashi O, Fujioka T, Kishi M, Normoto N, Iwasaki Y, Kurihara T. Guillain-Barré syndrome with optic neuritis and cytomegalovirus infection. J Peripher Nerv Syst 2005;10:340-341.

4. Durand MC, Goulon-Goéau C, Schweitzer A, Chéliout-Héraut F, Raphael JC, Gajdos P. [Electrophysiologic study of 10 cases of Miller Fisher syndrome]. Rev Neurol (Paris) 2001;157:72-79.

5. Zgorzalewicz M, Zielińska M, Kilarski D. [Brain stem auditory and visual evoked potentials in children and adolescents with Guillain-Barré syndrome]. Neurol Neurochir Pol 2004;38:S31-S37.

6. Wong V. A neurophysiological study in children with Miller Fisher syndrome and Guillain-Barre syndrome. Brain Dev 1997;19:197-204.

7. Topçu M, Ergin M, Nurlu G, Renda Y, Kanra G, Seçmeer G. Evoked potentials in Guillain-Barré syndrome. Turk J Pediatr 1993;35:79-85.

8. Asbury AK, Cornblath DR. Assessment of current diagnostic criteria for Guillain-Barré syndrome. Ann Neurol 1990;27 Suppl:S21-S24.

9. Research criteria for diagnosis of chronic inflammatory demyelinating polyneuropathy (CIDP). Report from an Ad Hoc Subcommittee of the American Academy of Neurology AIDS Task Force. Neurology 1991; 41:617-618.

10. Van der Meché FG, Van Doorn PA, Meulstee J, Jennekens FG; GBSconsensus group of the Dutch Neuromuscular Research Support Centre. Diagnostic and classification criteria for the Guillain-Barré syndrome. Eur Neurol 2001;45:133-139.

11. Hughes JR, Stone JL, Fino JJ, Hart LA. Usefulness of different stimuli in visual evoked potentials. Neurology 1987;37:656-662.

12. Delisa JA. Auditory and visual evoked potentials. In: Delisa JA, Lee HJ, Baran EM, Lai K, Spielholz N, Mackenzie K, editors. Manual of nerve conduction velocity and clinical neurophysiology. Philadelphia: Lippincott Williams and Wilkins,1994:294-304.

13. Morley JB, Reynolds EH. Papilloedema and the Landry-Guillain-Barré syndrome. Case reports and a review. Brain 1966;89:205-222.

14. Behan PO, Lessell S, Roche M. Optic neuritis in the Landry-GuillainBarré-Strohl syndrome. Br J Ophthalmol 1976;60:58-59.

15. Mori M, Kuwabara S, Fukutake T, Yuki N, Hattori T. Clinical features and prognosis of Miller Fisher syndrome. Neurology 2001;56:11041106.

16. Lüke C, Dohmen C, Dietlein TS, Brunner R, Lüke M, Krieglstein GK. [High-dose intravenous immunoglobulins for treatment of optic neuritis in Guillain-Barré syndrome]. Klin Monbl Augenheilkd 2007;224: 932-934.
17. Nadkarni N, Lisak RP. Guillain-Barré syndrome (GBS) with bilateral optic neuritis and central white matter disease. Neurology 1993;43:842843.

18. Pfausler B, Engelhardt K, Kampfl A, Spiss H, Taferner E, Schmutzhard E. Post-infectious central and peripheral nervous system diseases complicating Mycoplasma pneumoniae infection. Report of three cases and review of the literature. Eur J Neurol 2002;9:93-96.

19. Caccavale A, Mignemi L. Acute onset of a bilateral areflexical mydriasis in Miller-Fisher syndrome: a rare neuro-ophthalmologic disease. $J$ Neuroophthalmol 2000;20:61-62.

20. Hayashi Y, Fukuhara N, Yuki N. [Atypical Guillain-Barré syndrome associated with ophthalmoplegia and visual impairment following herpes simplex virus type 1 infection]. Rinsho Shinkeigaku 1994;34:724-726.

21. Robbins MS, Roth S, Swerdlow ML, Bieri P, Herskovitz S. Optic neuritis and palatal dysarthria as presenting features of post-infectious GQ1b antibody syndrome. Clin Neurol Neurosurg 2009;111:465-466.

22. Stevenson VL, Ferguson SM, Bain PG. Bickerstaff's brainstem encephalitis, Miller Fisher syndrome and Guillain-Barre syndrome overlap with negative anti-GQ1b antibodies. Eur J Neurol 2003;10:187.

23. Lolekha P, Phanthumchinda K. Optic neuritis in a patient with MillerFisher syndrome. J Med Assoc Thai 2008;91:1909-1913.

24. Chan JW. Optic neuritis in anti-GQ1b positive recurrent Miller Fisher syndrome. Br J Ophthalmol 2003;87:1185-1186.

25. Ginestal RC, Plaza JF, Callejo JM, Rodríguez-Espinosa N, FernándezRuiz LC, Masjuán J. Bilateral optic neuritis and Guillain-Barré syndrome following an acute Mycoplasma pneumoniae infection. $J$ Neurol 2004:251:767-768.

26. Colding-Jørgensen E, Vissing J. Visual impairment in anti-GQ1b positive Miller Fisher syndrome. Acta Neurol Scand 2001;103:259-260.

27. Ropper AH, Chiappa KH. Evoked potentials in Guillain-Barré syndrome. Neurology 1986;36:587-590.

28. An JY, Yoon B, Kim JS, Song IU, Lee KS, Kim YI. Guillain-Barré syndrome with optic neuritis and a focal lesion in the central white matter following Epstein-Barr virus infection. Intern Med 2008;47:15391542.

29. Ouhabi H, Bourazza A, Rouimi A, Boutaleb N, Mosseddaq R. [Bilateral optic neuritis and ponto-mesencephalic involvement shown by MRI in Miller-Fisher syndrome]. Rev Neurol (Paris) 1998;154:780-782.

30. Pakalnis A, Drake ME Jr, Barohn RJ, Chakeres DW, Mendell JR. Evoked potentials in chronic inflammatory demyelinating polyneuropathy. Arch Neurol 1988;45:1014-1016.

31. Stojkovic T, de Seze J, Hurtevent JF, Arndt C, Beaume A, Hache JC, et al. Visual evoked potentials study in chronic idiopathic inflammatory demyelinating polyneuropathy. Clin Neurophysiol 2000;111:22852291.

32. Uncini A, Gallucci M, Lugaresi A, Porrini AM, Onofrj M, Gambi D. CNS involvement in chronic inflammatory demyelinating polyneuropathy: an electrophysiological and MRI study. Electromyogr Clin Neurophysiol 1991;31:365-371.

33. Carvalho AA, Galvão MD, Rocha MS, Piccolo AC, Maia SC. [Miller fisher syndrome and optic neuritis: case report]. Arq Neuropsiquiatr 2000;58:1115-1117.

34. Cordonnier M, Caspers-Velu LE, Jacquemin C, van Nechel C, Tombroff M. Bilateral optic neuropathy and white dot syndrome following a mycoplasmal infection. Br J Ophthalmol 1993;77:673-676.

35. Fuller GN, Jacobs JM, Lewis PD, Lane RJ. Pseudoaxonal GuillainBarré syndrome: severe demyelination mimicking axonopathy. A case with pupillary involvement. J Neurol Neurosurg Psychiatry 1992;55: 1079-1083.

36. Hatanaka K, Nakasato N, Seki K, Kanno A, Mizoi K, Yoshimoto T. Striate cortical generators of the N75, P100 and N145 components localized by pattern reversal visual evoked magnetic fields. Tohoku J Exp Med 1997;182:9-14.

37. Bajaj NP, Rose P, Clifford-Jones R, Hughes PJ. Acute transverse myelitis and Guillain-Barré overlap syndrome with serological evidence for 
mumps viraemia. Acta Neurol Scand 2001;104:239-242.

38. Milla E, Zografos L, Piguet B. Bilateral optic papillitis following mycoplasma pneumoniae pneumonia. Ophthalmologica 1998;212:344346.

39. Toshniwal P. Demyelinating optic neuropathy with Miller-Fisher syndrome. The case for overlap syndromes with central and peripheral demyelination. J Neurol 1987;234:353-358.

40. Yoshino H, Maeda Y, King M, Cartwright MJ, Richards DW, Ariga T, et al. Sulfated glucuronyl glycolipids and gangliosides in the optic nerve of humans. Neurology 1993;43:408-411.
41. Chiba A, Kusunoki S, Obata H, Machinami R, Kanazawa I. Ganglioside composition of the human cranial nerves, with special reference to the pathophysiology of Miller Fisher syndrome. Brain Res 1997;745: 32-36.

42. Sasaki Y, Takubo H, Arai T, Machida Y, Ikebe S, Yuki N, et al. [Atypical Fisher syndrome with optic nerve involvement]. No To Shinkei 2001;53: 571-573.

43. Li H, Yuan J. Miller Fisher syndrome: toward a more comprehensive understanding. Chin Med J (Engl) 2001;114:235-239. 